\title{
Behaviour of Horses and Cattle at two Stocking Densities in a
}

\section{Coastal Salt Marsh}

\author{
S. Nolte ${ }^{1,2}$, C. van der Weyde ${ }^{3}$, P. Esselink ${ }^{1,4}$, C. Smit ${ }^{1}$, S. E. van Wieren ${ }^{5}$, J. P. Bakker ${ }^{1}$
}

\begin{abstract}
${ }^{1}$ Conservation Ecology, Groningen Institute of Evolutionary Life Sciences GELIFES, University
\end{abstract} of Groningen, P.O. Box 11103, 9700 CC Groningen, The Netherlands

\footnotetext{
${ }^{2}$ Applied Plant Ecology, Biocenter Klein Flottbek, University of Hamburg, Ohnhorststr. 18,
} 22609 Hamburg, Germany, Tel.: +49 40 42816-577, Fax: +49 40 42816-396, e-mail: stefanie.nolte@uni-hamburg.de

${ }^{3}$ Van Hall Larenstein University of Applied Sciences, PO Box 1528, 8901 BV Leeuwarden, The Netherlands

${ }^{4}$ PucCIMAR, Ecological Research and Consultancy, Boermarke 35, 9481 HD Vries, The Netherlands

${ }^{5}$ Resource Ecology Group, Wageningen University, 6708 PB Wageningen, The Netherlands

\section{Abstract}

Purpose: Livestock grazing has been practiced in salt marshes in the Wadden Sea area since 600 B.C. Currently livestock grazing is also applied for conservation management. However, effects of such grazing management on salt marshes are likely to vary depending on the species of livestock and stocking density due to differences in the behaviour of the animals. Yet, little is known about the behaviour of different livestock species and stocking densities grazing in salt marshes.

Methods: We studied the grazing behaviour of horses and cattle by focal observation in an experiment with four different grazing treatments on a coastal salt marsh. In all treatments we recorded diet choice, movement and grazing activity, and spatial distribution.

Results: Livestock species shared an overlap in diet choice. Yet, horses more often foraged on the short grass Puccinellia maritima, while the cattle diet contained a higher amount of Aster tripolium. 
Horses travelled longer distances per day and spent more time grazing than cattle. Spatial distribution of cattle was significantly clustered, while horses showed a random distribution utilizing the whole area.

Conclusions: Animal behaviour differs between livestock species and stocking densities with respect to diet choice, activity and spatial distribution.

Keywords: diet choice; focal observation; livestock species; conservation management; semi-natural grassland

\section{Acknowledgements}

We thank 'It Fryske Gea' for logistic support and for kindly permitting us to setup the experiment.

Gerrit van de Leest and Johannes Westerhof maintained the fences and inspected the well-being of the animals in the experiment. We acknowledge Anne-Marie van den Driessche for performing the chemical analysis and Nina Bhola for statistical advice. Adriënne Verburg and José de Jaeger are thanked for performing a preliminary study which enabled us to plan this research project. Dick Visser kindly prepared the figures. Esther Chang is acknowledged for improving the English of this manuscript. Sophie Prache and two reviewers gave valuable comments on a previous version of this manuscript. This research was funded by the Waddenfonds (project WF200451). 
Salt marshes are important ecosystems for the conservation of biodiversity in north western Europe, as they are inhabited by characteristic plant, bird and invertebrate species (Westhoff et al. 1993; Norris et al. 1997; Rickert et al. 2012). In these ecosystems livestock grazing for agricultural purposes has a long tradition (Esselink et al. 2002). In the past century many salt-marsh areas in the Wadden Sea region were abandoned, because livestock grazing was no longer economically feasible or because of the establishment of National Parks (Bakker et al. 2003). It was then found that abandonment leads to the spread and dominance of single species, such as the tall grass Elytrigia atherica (Veeneklaas et al. 2013). This development led to low plant diversity in abandoned marshes and therefore livestock grazing was suggested by a panel of international experts as a conservation management option to reduce encroachment of Elytrigia atherica (Bakker et al. 1993). However, the effect of grazing, not only on plants but also on other organisms such as birds and invertebrates, is likely to vary depending on behavioural differences e.g. between livestock species, between animals of different weight and different age, and between various stocking densities (Rook et al. 2004), i.e. the number of animals per ha (Stewart and Pullin 2008). These behavioural differences can be divided into three categories: (1) diet choice, (2) movement and grazing activity, and (3) spatial distribution. between livestock species when grazing in a similar area (Karmiris et al. 2011; Ferreira et al. 2013). However, some differences in the diet choice may be related to characteristics of the mouth anatomy, the digestive system, and differences in nutritional requirements of the livestock. Horses, as hind-gut fermenters, require a higher food intake than cattle, which are ruminants (Duncan et al. 1990). Additionally, horses, in contrast to cattle, have been found to consume more high-fibre forage such as fibrous grasses (Gordon 1989; Vulink and Drost 1991; Menard et al. 2002). Thus, we expect horses to include more grasses in their diet, and cattle to consume more forbs (i.e. herbaceous flowering 
1991; Menard et al. 2002), we expect the average fibre content of horses' diet to be higher. Furthermore, diet choice might also differ between stocking densities of one species, as animals in higher densities are often forced to include less preferred plant species into their diet (Crawley 1983). Additionally, smaller animals were found to be more selective, which is in line with the observation that also young and female animals, which are generally smaller than older or male animals, show a higher selectivity (Rook et al. 2004).

Differences in digestive systems among large herbivores also partly determine their patterns of movement and grazing activity. Ruminants can extract more nutrients from their forage (Duncan et al. 1990), while hind-gut fermenters compensate for this by having a higher daily food intake (Duncan et al. 1990; Ferreira et al. 2013). Therefore, the average time spent grazing per day of horses is expected to be longer in comparison to cattle. To acquire more forage it is probably also necessary for horses to have a higher movement activity and we therefore expect horses to travel on average longer distances per day compared to cattle. Additionally, cattle were found to spend on average between $31-38 \%$ of the time ruminating which includes staying in the same location (Dale et al. 2008; Abrahamse et al. 2009). The movement and grazing activity of the animals could thus also potentially determine the spatial distribution of the animals within the available space. If cattle stay in the same position to ruminate for a certain proportion of the day, they probably show a more clustered distribution compared to horses.

In addition to differences between livestock species, stocking density is also likely to influence movement and grazing activity and spatial distribution of the livestock. At high stocking densities, the depletion of preferred food plants might also lead to increased movement activity as animals are forced to search for food plants. This search for food plants may affect the spatial distribution of the animals. Furthermore, experience was found to affect grazing activity, as sheep, cattle and goats were found to spent up to $40 \%$ more time eating in an unfamiliar environment (Provenza and Balph 1987). 
Additionally age and size of the animals might affect patterns of movement and grazing activity with smaller and younger animals showing a higher step rate (Rook et al. 2004).

We studied the grazing behaviour of horses and cattle at two different stocking densities in a mainland salt marsh, focusing on diet choice, movement and grazing activity, and spatial distribution. More specifically, the following four hypotheses were tested: 1) horses at high stocking densities forage on dominant grasses more than cattle at low stocking densities, 2) Forage quality is higher in the diet of horses at high stocking densities than cattle at low stocking densities, 3) livestock activity is higher for horses at high stocking densities than cattle at low densities, and 4) the higher activity of horses at high stocking densities leads to a more random spatial distribution than cattle at low stocking densities.

\section{Methods}

\section{Study Site}

The research area, 'Noord-Friesland Buitendijks' (NFB) $\left(53^{\circ} 20^{\prime} 11^{\prime \prime} \mathrm{N}, 5^{\circ} 43^{\prime} 40^{\prime \prime} \mathrm{E}\right)$, is a temperate salt marsh located on the north coast of The Netherlands. Average annual precipitation is $820 \mathrm{~mm}$ and average annual temperature is $9.5^{\circ} \mathrm{C}$ (data Royal Netherlands Meteorological institute). On average the area lies $0.6 \mathrm{~m}$ above mean high tide (MHT) and the local tidal range is $2.1 \mathrm{~m}$. NFB is of anthropogenic origin because marsh development was facilitated by ditching and the construction of sedimentation fields. As a result, the marsh is characterized by an evenly distributed drainage pattern and a rather flat relief with a gentle slope down to an area of intertidal mudflats. Therefore the area is convenient for a large experimental setup as abiotic conditions and vegetation composition will be comparable between treatments.

The experimental treatments, consisting of four different grazing treatments within two replicate blocks (Fig. 1), were established in the spring of 2010. Before the start of the experiment, 
both blocks had been subject to intensive grazing with approximately 1.0 cattle per ha during the summer months. Each block was subdivided into five paddocks (ca. 11 ha each) including one ungrazed paddock which is not used in this study. Each paddock includes an elevation gradient from North to

121 South and is comprised of both low and high salt marsh zones. The high-marsh zone was dominated by two vegetation types, namely the brackish-flooded grassland type and the Elytrigia repens-type.

123 While the brackish-flooded grassland type was dominated by Agrostis stolonifera, the Elytrigia repens-

124 type was dominated by Elytrigia repens, but often contained a large amount of Elytrigia atherica. The

125 low marsh was mainly formed by two vegetation types. The first one is the Puccinellia-type, including

126 a varying cover of Aster tripolium. Secondly, we included the Salicornia spp./Suaeda maritima-type,

127 which is mainly dominated by these annual plants, to the low marsh. A detailed vegetation map can 128 be found in Supplementary 1. 


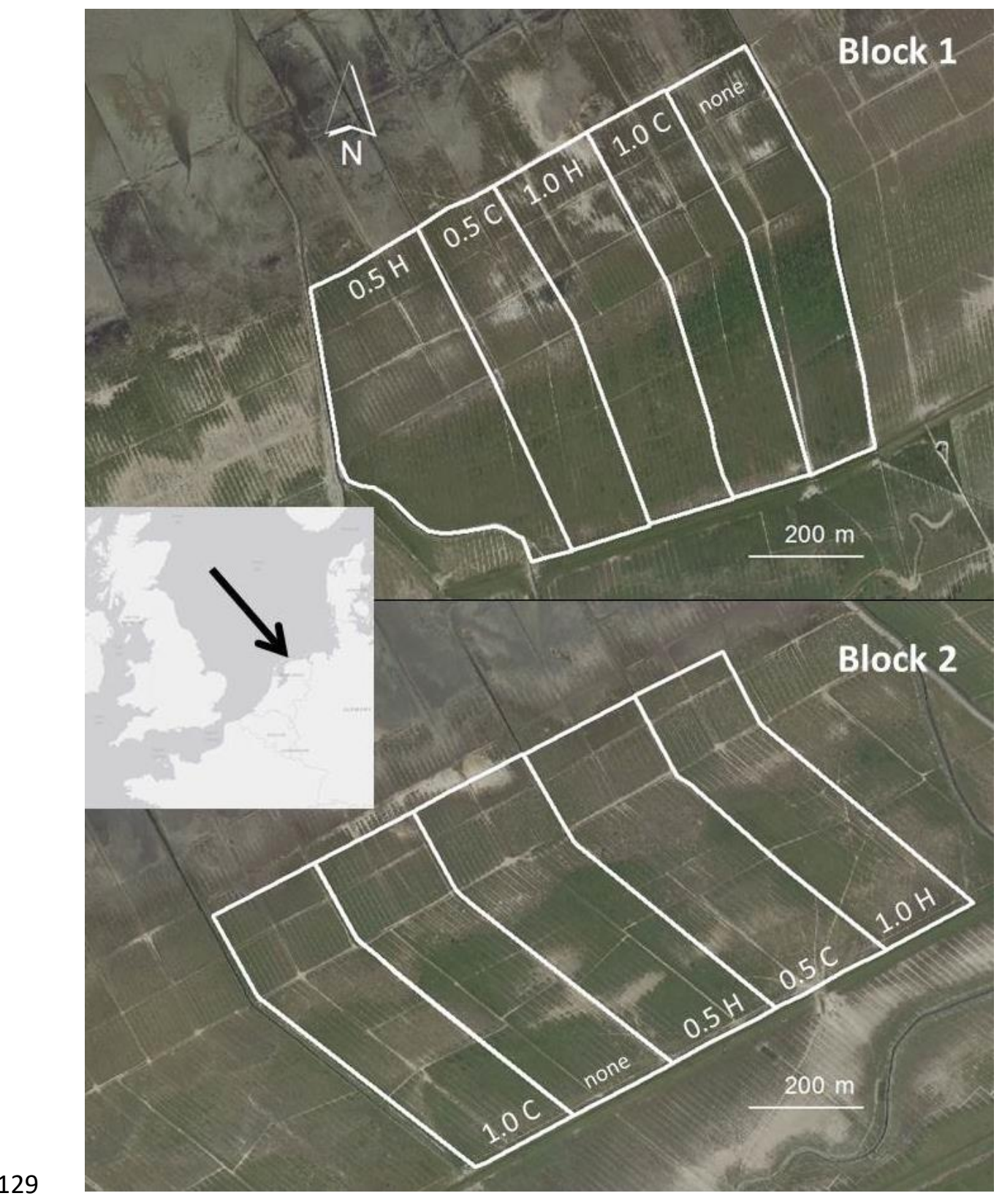

130 Fig. 1 Experimental setup with paddocks (white line) and freshwater source $(\star)$. Treatment is shown with letters (C=cattle 131 and $\mathrm{H}=$ horses) and a number representing stocking density per ha. The ungrazed paddock, which was not used in this study, 132 is indicated by the word 'none' The following grazing treatments were applied within each block: cattle grazing with 5 animals ( 0.5 per ha) and 10 animals ( 1.0 per ha) per paddock and horse grazing with 5 animals ( 0.5 per ha) and 10 animals (1.0 per ha) per paddock. A stocking density between 0.5 and 0.6 animals/ha was proposed by Andresen et al. (1990) and Kleyer et al. (2003) as being the most beneficial for plant-species diversity in salt marshes in grazing experiments with cattle. However, we expect the same number of 
horses per ha to have a much greater effect. Therefore, the stocking density of 1.0 animals per ha, which is higher than the recommendation of Andresen et al. (1990) and Kleyer et al. (2003), is referred to as high density here, while 0.5 animals per ha treatment is referred to as the low density. All cattle were female, non-lactating animals of the breed Holstein-Friesian, weighed ca. $600 \mathrm{~kg}$ and were 2 or 3 years old. The horse herd consisted of both male and female animals of the breed KWPN (Koninklijk Warmbloed Paardenstamboek Nederland), which were all older than 2 years and weighed ca. $700 \mathrm{~kg}$. Animals were obtained from local farmers and remained in the paddocks from June to October, enabling animals to adapt to the area before focal observations started in August. Access to a freshwater source was always given in the southern end of each paddock.

We recorded the diet choice, activity and spatial distribution of the animals during observation sessions in August and September 2010 following the methodology described by Esselink et al. (2000). Each observation session consisted of hourly observations of all animals from noon on the first day to noon on the following day. No observations were performed during the night, however, because recognition of selected plant species was too difficult. During an observation, the animals were carefully approached without disturbing them (Dumont et al. 2007b) and the animals apparently were not influenced by the presence of the observers. Four observation sessions per block were carried out to 13 by the end of September because of the shortening of the daylight period.

To quantify the diet choice of the animals we noted the plant species of the third bite for each individual animal in each observation. This was done to avoid a bias towards easily identifiable plant species (Dumont et al. 2007b). In the case of mixed bites we considered the dominant plant species. There were no difficulties in recognizing the plants from the position of observation. The vegetation type where each animal stayed was also recorded. 
The recording of the diet choice was also used to calculate the average forage quality of the diet based on the mean neutral detergent fibre (NDF) of the plant species. We collected samples of all plant species available to the livestock in the area to assess the forage quality of species based on the neutral detergent fibre (NDF). The mean NDF values of the species were then used to calculate the mean NDF of the diet based on the species composition chosen by the animals of the group. A high NDF, which includes cellulose, hemicellulose and lignin as major components (Van Soest et al. 1991), may indicate a relatively low forage quality and digestibility. Plant material was collected by mimicking animal bites, and for each sample bites were taken from several stands of a plant species. One sample was taken from each cattle-grazed paddock $(n=4)$ to test for possible differences in NDF associated with smallscale abiotic variations and between stocking densities. Samples were collected at the beginning of September, representing the peak of the growing season and also the season in which the animal observations were conducted. Due to time constraints, horse-grazed paddocks were not sampled and sampling was not repeated during the grazing season. All samples were dried at $70^{\circ} \mathrm{C}$ within one day after collection, then ground, sieved (1-mm sieve) and analysed for NDF (NDF in \% of dry matter weight) (Van Soest et al. 1991).

During each observation the following behaviour categories were distinguished for each individual: grazing, walking, resting and drinking. At the end of each observation, the position of the group of animals was recorded with a handheld GPS. We used the group as the unit of analysis as animals were mainly observed to remain close together (Hampson et al. 2010). 
We performed a Canonical Correspondence Analysis (CCA) to investigate differences in diet choice between horses and cattle and between stocking densities using the statistical software 'CANOCO' version 4.5 (ter Braak and Šmilauer 2002). All other analyses were performed using the statistical software ' $R$ ' version 2.15.2 (R Development Core Team 2013). For the CCA analysis we counted plant species chosen by all individuals within one paddock and observations to obtain the diet choice of the group. The diet choice then consists of several plant species and was expressed as a percentage value for each plant species. Thus, if for example one out of ten horses in the group in one observation chose the plant species Aster tripolium, this species would represent $10 \%$ of the diet choice of the group. The diet choice of each observation was used as species response variables in the CCA. As factors, we included livestock species and stocking density. The following random factors (called covariables in CCA) were used: block, vegetation type in which the animals were observed, and time of day. Random factors were selected using the forward selection procedure during which each random factor is added for significance. Forage Quality

We tested differences of NDF between samples from different blocks using t-tests for each of the average NDF of the plant species in the diet (Eq. 1). analysed plant species. As slight differences between blocks were only found in two out of 15 tested species (Supplementary 2) we decided to pool samples of the same species in all cases for further analysis. We calculated the average NDF of plant species found in the diet of cattle and horses at the two stocking densities per observation. First, the NDF of each plant species (e.g. NDF $F_{a}$ of species $a$ ) in the observation was multiplied by the number of times $\left(n_{a}\right)$ this species was recorded. Then the sum of all species was divided by the total number $(N)$ of bites occurring in the observation to obtain the

$$
\text { average } N D F=\frac{\sum\left(N D F_{a} * N_{a}\right)}{N}
$$


This average NDF value was used as the response variable in a model containing livestock species, stocking density, and their interaction term, as well as block as explanatory variables. We detected heterogeneity of variance with a greater spread of residuals in cattle compared to horses, and at lower stocking densities compared to higher stocking densities and therefore applied a generalized least squares model (GLS) using the 'nlme' package (Pinheiro et al. 2013) with a combination of variance structures (varComb) allowing for different spreads both per livestock species and per stocking density (Zuur et al. 2009). The optimal correlation structure was found by fitting GLS models with various correlation structures and comparing these to a model without a correlation structure using the Akaike information criterion (AIC). Delta AIC is calculated by subtracting the AIC of the best model from the model in question. A delta $\mathrm{AIC}<2$ indicates substantial evidence for the model, while values between 3 and 7 suggest less support and with a delta AIC $>10$ the model can be seen as very unlikely (Burnham and Anderson 2002). Additionally, Akaike weights represent the ratio of delta AIC values for each model relative to the whole set of $R$ candidate models, thereby indicating the probability that the model is the best among the whole set of candidate models (Burnham and Anderson 2002). An Akaike weight of 0.69 , for example, can be interpreted as a probability of $69 \%$ that the model is the best among the tested models. This model selection procedure is also applied in all further analyses. An exponential correlation function was applied as the optimal correlation based on based on AIC, delta AIC and Akaike weights.

To detect potential temporal and spatial autocorrelation we used the auto-correlation function ('acf') and the variogram function ('variogram'), respectively. The fitted variogram revealed spatial autocorrelation, while no temporal autocorrelation was detected. Therefore, we included a correlation structure. The optimal correlation structure was found by fitting GLS models with a spherical, linear, rational quadratic, Gaussian, and exponential correlation structure (Supplementary 3). After the optimal correlation structure is chosen, factors were dropped from the full model in all possible combinations and the best model selected based on AIC, delta AIC and Akaike weights. 
We digitized the position of the group of animals within each paddock with GPS-coordinates during each observation session using the software ArcGIS 10 (ESRI 2011). We then calculated the distance between the two coordinates of each chronological pair of observations during the observation session. This distance is the minimum distance the animals walked in one hour to reach the second point of the chronological pair. We used this simple measure as an index for the movement activity of the animals following Pepin et al (2009) and Elizalde-Arellano et al (2012). The difference between treatments was analysed using a generalized linear mixed model (GLMM) approach applying the glmer-command of he 'Ime4' package (Bates et al. 2014). A Gamma distribution is assumed as the response variable is continuous and contains only positive values. The model results show the variance explained by the block to be 0.00 , indicating that the random factor is unnecessary. Therefore, a GLM approach was applied with the full model including livestock species, stocking density and their interaction effect, as well as block as explanatory variables. No temporal or spatial autocorrelation was detected. The full model was compared to all other possible models using AIC, delta AIC and Akaike weights.

The difference in proportion of time the different livestock species spent grazing per observation session as a second measure of activity was also first analysed with a GLMM, assuming a binomial distribution. We started with a full model including livestock species, stocking density and the interaction effect, as well as block as a random effect applying the glmer-command of the 'Ime4' package (Bates et al. 2014). The model results show the variance explained by the block is very low (0.04), indicating that the random factor is unnecessary. Therefore, a GLM approach was applied with the full model including livestock species, stocking density and their interaction effect, as well as block as explanatory variables. Overdispersion was detected using both the binomial and quasibinomial approach. Therefore, a negative binomial model was applied. No temporal autocorrelation between observation sessions was detected. Spatial autocorrelation could not occur, as data points represent 
entire observation sessions and not single observations with coordinates. The full model was compared to all other possible models using AIC, delta AIC and Akaike weights.

Spatial Distribution

We compared the spatial distribution of the animals as a group in each paddock with random-point distributions using the Average Nearest Neighbour Distance tool in ArcGIS 10. The position of the group, not each separate individual, at each focal observation is represented by one point. The Average Nearest Neighbour Distance tool measures the distance between each of these points and their nearest neighbouring point and calculates a ratio of observed to expected random average nearest neighbour distance (NN-ratio). A NN-ratio less than 1 indicates clustered points, whereas a NN-ratio greater than 1 indicates dispersed points. Additionally, the z-scores and p-values in the average nearest neighbour distance tool output indicate whether the observed average nearest neighbour distance significantly differs from an average nearest neighbour distance of a random spatial distribution of points with the same characteristics (number of points and available area) (Dixon 2002).

\section{Results}

\section{Diet Choice}

In the CCA, we found that $8.6 \%$ of the variation in the diet choice data was explained by the first two axes (Fig 2). The model was significant with $p<0.005$ (F-ratio 4.295), indicating significant differences between the diet choice of livestock species and at different stocking densities. We focus on the four plant species representing at least $10 \%$ of the diet choice, namely Agrostis stolonifera, Aster tripolium, Elytrigia repens and Puccinellia maritima. Aster tripolium was more often found in the diet of cattle compared to horses and at low compared to high stocking densities as indicated by the position of the species in the CCA biplot (Fig. 2). In contrast, Puccinellia maritima was found more often in the diet of 

appear in the CCA biplot (Fig. 2), which only depicts species with a species-fit-range above $1 \%$. If depicted, the species would appear in the centre of the plot, indicating that the amount of the species in the diet did not differ between livestock species or stocking densities.

Figure 2

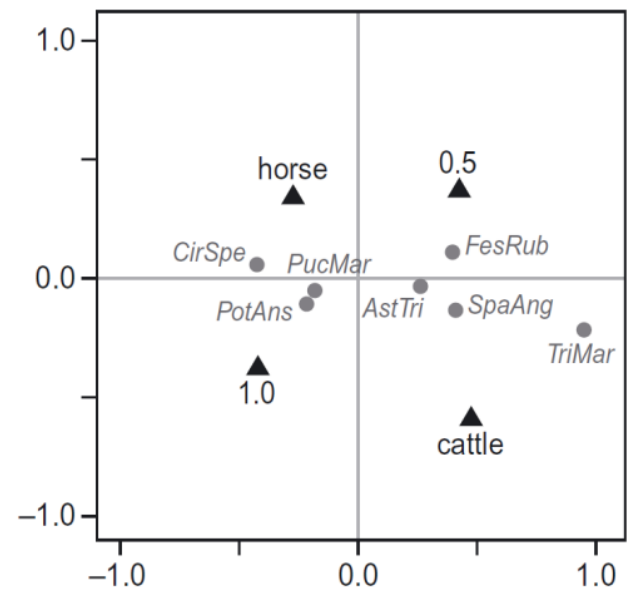

289

Fig. 2 Biplot of CCA showing differences between the diet choice of cattle and horses at different stocking densities. Species (second axis), 0.415 (third axis), 0.373 (fourth axis). Monte Carlo Permutation F-ratio $=0.075$ (first axis), $p$-value $=0.002$

The average NDF of the diet of cattle is lower than that of horses and is lower in low than high stocking densities (Fig. 3). The final GLS model analysing the average NDF of plant species found in the diet included the explanatory variables livestock species, stocking density and the interaction effect (Table 1). The best model is only marginally better than the model including no interaction effect (delta AIC 0.57) and the two models including block and the interaction effect of livestock species and stocking density (delta AIC 0.95) and or the factors livestock species and stocking density without interaction effect (delta AIC 1.64), respectively. 
Figure 3

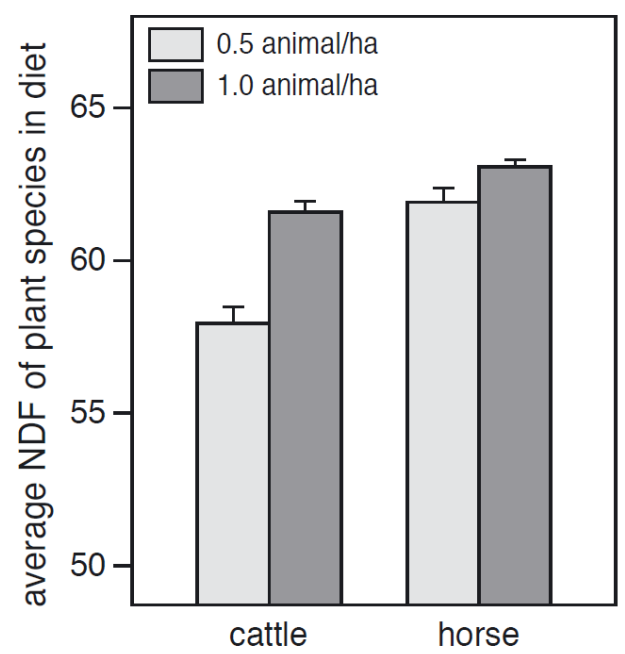

301

302 Fig 3 Average NDF of plant species found in the diet $r$ in the diet of animals in the four different grazing treatments. Light grey bars represent low stocking densities and dark grey bars indicate high stocking densities. Error bars represent the standard error

Activity

Horses were more active than cattle, as indicated by the larger distance between two successive observations (mean distance horses $=152 \mathrm{~m}, \mathrm{SD}=124$; Cattle $=121 \mathrm{~m}, \mathrm{SD}=99$ ). The best model explaining the minimum distance that livestock travelled between observations contained only livestock species (Akaike weight 0.35 , Table 1). However, the best model is only marginally better than three other models (delta AIC $<2$ ), including the model with both livestock species and stocking density as explanatory variables. The mean distance travelled by animals in low stocking densities (132 $m, S D=113)$ was slightly smaller than of animals in high stocking densities $(140 \mathrm{~m}, \mathrm{SD}=115)$. and block, whereas stocking density and the interaction term were dropped (Table 1). The average length of daylight period of the day during the study was 14.5 hours. Thus, horses spent on average 12 hours, and cattle 7 hours, per day grazing. The best model is only marginally better than the model 
including livestock species, stocking density and block (delta AIC 1.92). However, the latter model has a $30 \%$ lower probability of explaining the data when the Akaike weights of both models are compared. The mean grazing time of animals in low and high stocking densities is $65.7 \%(S D=18.6)$ and $65.1 \%$

$321 \quad(S D=21.9)$, respectively.

322

\section{Spatial Distribution}

The results of the average nearest-neighbour analysis indicate that three out of four horse paddocks showed a random spatial distribution of the animals. Horses neither clustered together nor dispersed evenly over these paddocks as indicated by the NN-ratio close to 1 (Fig. 4). Only one of the horsegrazed paddocks was characterized by a high NN-ratio and a distribution that was significantly different from random. This indicated that in this paddock, the horses spread evenly over the whole paddock. Cattle on the contrary, had a significantly clustered distribution in three out of four paddocks, as indicated by a NN-ratio $<1$, with a nearly significant trend $(p=0.079)$ towards clustering in the fourth paddock (Fig. 4).

Figure 4

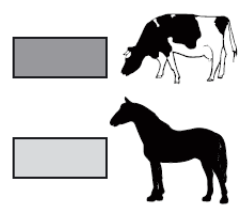

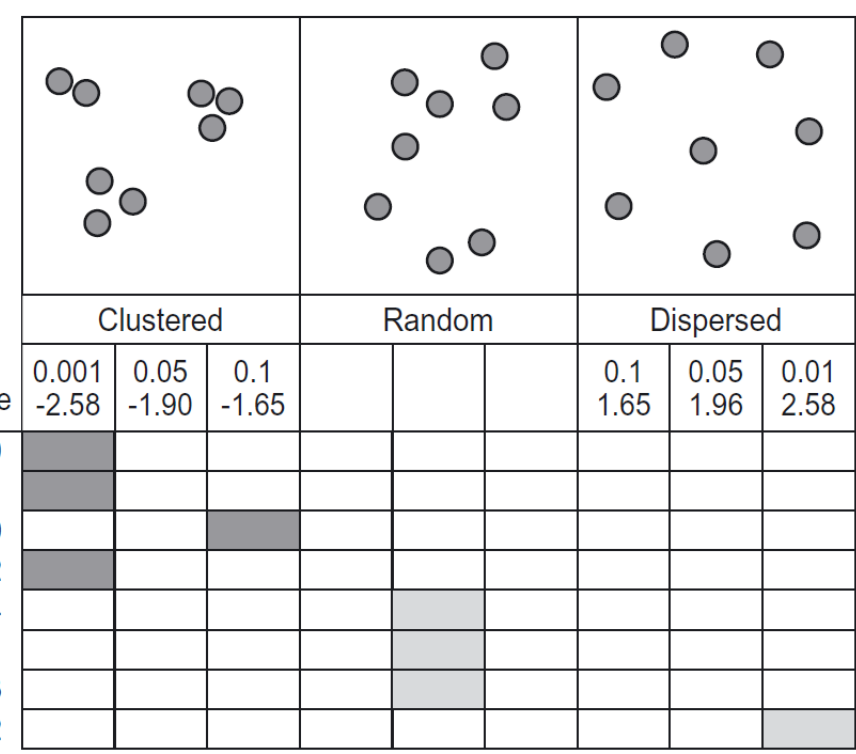

Livestock Density Block NN ratio $Z$ score $p$ value

\begin{tabular}{llllll}
\hline Cattle & 1.0 & 2 & 0.735 & -3.656 & 0.000
\end{tabular}

$\begin{array}{llllll}\text { Cattle } & 1.0 & 1 & 0.776 & -3.178 & 0.001\end{array}$

$\begin{array}{llllll}\text { Cattle } & 0.5 & 2 & 0.874 & -1.754 & 0.079\end{array}$

$\begin{array}{llllll}\text { Cattle } & 0.5 & 1 & 0.777 & -3.158 & 0.002\end{array}$

Horses $\quad \begin{array}{lllll}1.0 & 2 & 0.954 & -0.637 & 0.524\end{array}$

$\begin{array}{llllll}\text { Horses } & 1.0 & 1 & 1.002 & 0.023 & 0.981\end{array}$

$\begin{array}{llllll}\text { Horses } & 0.5 & 2 & 0.947 & 0.750 & 0.453\end{array}$

$\begin{array}{llllll}\text { Horses } & 0.5 & 1 & 1.151 & 2.145 & 0.032\end{array}$

Fig. 4 Average nearest-neighbour distance between positions of livestock groups obtained by pooling all observations from 
In this study we found differences between two livestock species and two stocking densities regarding

1) diet choice, 2) forage quality, 3) movement and grazing activity, and 4) spatial distribution. We found a general overlap in diet, although some plant species were found more often in the diet of either horses or cattle, and either high or low densities. The forage quality of the diet of cattle was higher than that of horses, and was also higher in the diet of animals grazing in lower than higher densities. Furthermore, we found horses to show a higher movement and grazing activity. Finally we found that cattle, in contrast to horses, show a more clustered distribution. found more often in the diet of cattle, while the horse's diet contained more Puccinellia maritima. No difference between the grazing treatments was found for Agrostis stolonifera and Elytrigia repens. We expected the diet choice to be explained by the forage quality of the plant species. We found that the fibre content (NDF) differed between horses and cattle, even though differences between treatments were small. This is in line with literature, reporting that horses as hind-gut fermenters can better tolerate high-fibre forage, whereas cattle are more selective for forage with lower fibre content (e.g. Gordon 1989). According to our expectation cattle grazed more frequently on Aster tripolium, which had a relatively low NDF content (43.3\% DM), while horses grazed more often on Puccinellia maritima, which, according to our results, had a relatively high NDF content (64.4 \%DM). However, in contrast to our expectations, no difference between the grazing treatments was found for Agrostis stolonifera, even though this species also has a relatively high NDF content (62.5\%). This might indicate that NDF is not always the most reliable indicator of forage quality. In a study by Duncan et al. (1990) for example, the explained variance in the relationship between NDF and dry-matter digestibility was relatively low. Additionally, data published in Silliman et al. (2014) showed Puccinellia maritima to 
crude protein content. However, in the latter case the sampling technique might have played a role, as Silliman et al. (2014) only analysed young leaf tissue.

Another factor which might explain the preference of horses for Puccinellia maritima is the plants prostrate growth form, which can be better exploited by horses. Previous studies also found a preference of horses for shorter grasses in comparison to cattle (Menard et al. 2002; Cornelissen and Vulink 2015). Finally, horses are less able to tolerate secondary metabolites than cattle (Krysl et al. 1984; Menard et al. 2002). These secondary metabolites are more common in dicotyledonous plants (e.g. Aster tripolium). Thus, the presence of secondary metabolites might be a reason for horses to avoid these plants. Lellau and Liebezeit (2001) found both phenolics and tannins in Aster tripolium, while these secondary components could only be detected in some grasses and not with all tests.

When comparing different stocking densities, we found a tendency for animals at higher densities to include more of the less preferred food plants into their diet, possibly because of the depletion of preferred species such as Aster tripolium (Cornelissen and Vulink 2015). The extent to which Puccinellia maritima will be included when comparing different stocking densities might be explained by interference between animals, which has been found to result in animals being less selective at higher densities, even when preferred species were abundant (Crawley 1983). This shift might however also be caused by depletion of more palatable plant species at higher stocking densities (Crawley 1983; Augustine and McNaughton 1998; Cornelissen and Vulink 2015). An indicator for this depletion of forage can be seen in the stronger reduction of mean canopy height at high compared to low densities and with horse grazing compared to cattle grazing described for the study area by Nolte et al. (2014). The higher forage intake rate we found based on average hours per day spent grazing, leads to a general depletion of forage. We can conclude that there are differences in the diet choice between livestock species and stocking densities. These differences are likely caused by species-specific differences in digestive physiology, foraging apparatus and range of movement, and the depletion of preferred food plants at higher stocking densities. 
Horses had a higher movement and grazing activity than cattle in that they spent a greater part of the day foraging and covered greater distances. Cattle, in contrast to horses, spent a large part of their time ruminating and during these periods only travelled very short distances or remained at the same spot. Our results are supported by other studies, which found horses and other equids to forage $50 \%$ longer than ruminants such as cattle in French wetlands (Menard et al. 2002). Feeding trials in zoos, during which two forages were presented to different sub-species of bovids ranging from $80 \mathrm{~kg}$ sheep to $800 \mathrm{~kg}$ African buffalo (Syncerus caffer), and different species and breeds of equids ranging from $140 \mathrm{~kg}$ Wild ass (Equus hemionus) to $450 \mathrm{~kg}$ domestic horse, also showed that similar sized hind-gut fermenters have higher rates of food intake than ruminants (Duncan et al. 1990). This higher food intake rate is necessary for hind-fermenters to compensate for their lesser ability to digest plant material (Duncan et al. 1990).

The results of a generally higher activity of horses are consistent with the results of the spatial distribution of the groups of animal. We found the horse groups to be distributed more randomly over the marsh using the entire area, whereas the cattle groups tended to be more clustered and remained longer at the same spot. This distribution can be explained by the ruminating behaviour of cattle which therefore remain stationary for longer periods. Putman et al. (1991) also found horses to use a higher percentage of the total area, with is in line with our results of a wider and more random spread of the group of horses within the paddock. Furthermore, the spatial distribution of the groups of animals might have been affected by the position of the group in the neighbouring paddock. However, we did not observe social interaction between groups in different paddocks during our observation sessions and the positions of groups from two paddocks were never found directly next to each other. technically difficult to perform and therefore usually also excluded in other studies (Putman et al. 1991; Dumont et al. 2007b; Ferreira et al. 2013; Cornelissen and Vulink 2015). Furthermore, a study on the grazing behaviour of cattle showed that grazing at night only represented $10 \%$ of the total daily 
eating time (Rutter et al. 2004) and can thus be neglected. Grazing at night, however, is known to play an important role for horses (Boyd et al. 1988). This suggests that the differences described in this study may be greater if night grazing would have been included. Furthermore, we were unable to perform observations representing the beginning of the grazing season. Yet, grazing behaviour was found to differ between seasons (Dumont et al. 2007a). In their study of heifers, including observations in spring, summer and autumn, Dumont et al (2007a) found NDF of the diet, time spent grazing, the proportion of area used by the animals, the number of bites per step and selectivity for short patches to vary with season. However, a significant interaction effect between season and stocking density was only found in one of the studied response variables, namely the number of bites per step. This result indicates that for all other measured variables representing foraging behaviour differences between stocking densities remained similar in all three seasons. Therefore, we are satisfied that the differences between livestock species and between stocking densities that we found are likely to be representative of the whole grazing season.

Additionally, the conclusion drawn from this study may only apply to livestock of a comparable size, age and breed, and which are not lactating, as these factors were found to affect behaviour (Rook et al. 2004; Metera et al. 2010). Young animals were found to be more selective (Rook et al. 2004) and all animals in our study were of a comparable age. Furthermore, lactating animals were found to compensate their higher nutritional requirements by increasing their grazing time as demonstrated e.g. for lactating cattle (Gibb et al. 1999). However, all the animals in our study were not lactating. Size also affects behaviour as small animals are generally more selective as they require more energy relative to their gut capacity than larger animals (Rook et al. 2004). In the present study, horses were slightly heavier than cattle, however, our results are confirmed by other studies (e.g. Duncan et al. 1990; Menard et al. 2002), and therefore the observed differences in behaviour were probably not caused by weight differences, but by species differences. As quantifying these differences between species was the aim of the study we chose to compare the same number of animals per ha. Furthermore, such a stocking density with respect to animals/ha, rather than a stocking density based 
on biomass removal, is commonly used in management recommendations and therefore makes our study easily applicable for management questions.

Finally, as we were concerned that the presence of the observer may have affected the behavior of the animals, we wanted to minimize any potential observer effect. To do so, we tried to accustom the animals to the observer in July, prior to the start of observations in August. This approach was successful. While a direct reaction to the presence of the observers by the animals such as walking away or looking up still happened in July, such behaviour was not observed from August onward. Furthermore, alternative methods to study animal behavior include other sources of bias. The collection of droppings followed by an analysis of the plant remains in the dung, for example, is biased towards less digestible plants and only yields limited information about the spatial distribution and activity of the animals. Other approaches such as the use of GPS collars and/or cameras could not be applied due to limited funds.

Another common livestock species used on salt marshes is sheep. Sheep differ from larger livestock species such as cattle and horses in that they are generally more selective for higher quality forage as small herbivores generally require more energy relative to their gut capacity than large ones (Rook et al. 2004). The effect of sheep in different densities on the vegetation of salt marsh has been extensively studied in the German Wadden Sea (Berg et al. 1997; Kiehl et al. 2001; Schröder et al. 2002; Kiehl et al. 2007). While these previous studies have focused on the effects of different stocking densities of sheep on salt marsh vegetation, studies comparing different livestock species within the same experimental setup are scarce. Only one study on salt marshes included both cattle and sheep (Jensen 1985), but in a mixed grazing treatment where comparisons between livestock species are difficult. Additionally, Jensen (1985) did not investigate the animal behaviour. Therefore, we focused on the comparison of different livestock species and, due to the limited space, could only apply two different stocking densities. Adding a third intermediate or lower stocking density could, however, 
have yielded interesting information about whether the selectivity of the animals indeed shifts with decreasing availability of preferred plant species.

Due to practical limitations, the area of salt marsh available for the experiment only allowed the establishment of two blocks, which is a low number of replicates for statistical analyses. Therefore, abundance of species between blocks as indicated by the area covered by vegetation types dominated by these species in the vegetation map (Supplementary 1) slightly differed per block. This availability of plant species might have led to slight differences in the NDF and activity between blocks. Therefore, the conclusions drawn from this study especially with regard to the amount of specific plants in the diet may only be applied to similar sites along the western part of the Dutch Wadden Sea mainland coast. However, as our results with regard to differences between livestock species in forage quality and activity are in line with previous studies(Duncan et al. 1990; Menard et al. 2002), these may be applied more generally.

The available space for the experiment also limited the paddock size to $11 \mathrm{ha}$, which is comparable to that of e.g. the experiment described by Kiehl et al. (1996). If a larger area, such as e.g. the entire 55 ha of one block, would have been available to the same number of animals, we would expect smaller differences in diet choice between the stocking densities, as preferred forage plants might not have been depleted. However, if the stocking density would have remained constant in such a larger area, we would expect no change in the diet selection assuming that the proportion of the different plants available in the area stays the same. Additionally, animals might have travelled longer distances per day. Within the experimental setup the maximum distance that animals could walk by crossing the paddocks diagonally was $760 \mathrm{~m}$ and $700 \mathrm{~m}$ for block 1 and 2, respectively. If the animals could have moved through the whole block, the animals could have increased the maximum length to $1000 \mathrm{~m}$ and $1300 \mathrm{~m}$ respectively. The average distance moved by a group of horses in paddocks 
the relative differences between the livestock species would probably have been similar if the paddocks would have been larger.

The differences in behaviour described in this study can be used to explain differences in the damage and the amount of flowers per individual plant of the target species Aster tripolium found by Nolte et al. (2013) within our study area. As Aster tripolium was more often found in the cattle compared to the horse diet, we would expect more damage to Aster tripolium in cattle-grazed treatments. This expected result was, however, only found in low stocking densities, where cattle may cause more damage than horses due to selective defoliation (Nolte et al. 2013). In contrast, at high stocking densities horses caused more damage to Aster tripolium compared to cattle (Nolte et al. 2013). An explanation of this observation might be that although cattle show a preference for Aster tripolium, the overall higher activity of horses found in our study might cause more damage as a result of trampling (Nolte et al. 2013). This example also shows how differences in grazing behaviour can cascade through the ecosystem on different levels, as Aster tripolium is an important food source for various invertebrates (Meyer et al. 1995; Rickert 2011; van Klink et al. 2016).

In addition to effects on individual plant species, knowledge of the differences in grazing behaviour between livestock species and stocking density is useful to understand effects on vegetation structure. In the same experiment as described here, horses were found to create larger patches of similar vegetation canopy height (Nolte et al. 2014). It is argued by Nolte et al. (2014) that the larger patches are caused by the higher forage intake of horses. Additionally, horses were found to create very short swards, while cattle rip off part of the vegetation with their tongue (Gordon 1989; Dumont et al. 2012) and therefore probably create a more heterogeneous canopy structure. The differences in vegetation structure also have indirect effects on the ecosystem, for example by affecting some ground-nesting birds such as Oystercatcher and Redshank, which prefer taller patches of vegetation to build their nests (Mandema et al. 2014). However, breeding birds can also be affected 

area (Mandema et al. 2013). Finally, it should also be considered how differences in behaviour can

510 affect sediment dynamics in grazed salt marshes. In the experimental setup described here horses and

511 high stocking densities were found to reduce accretion rates directly by increasing soil compaction

512 and indirectly by reducing vegetation structure and thereby decreasing sediment-deposition rates

513 (Nolte et al. 2015). Again this finding can be explained by the behavioural differences described here.

514 We suggest that behavioural studies are an important baseline to understand effects of different

515 livestock grazing treatments on salt marshes (van Klink et al. 2016). 
Abrahamse PA, Tamminga S, Dijkstra J (2009) Effect of daily movement of dairy cattle to fresh grass in morning or afternoon on intake, grazing behaviour, rumen fermentation and milk production. J Agric Sci 147:721-730. doi: 10.1017/S0021859609990153

Andresen H, Bakker JP, Brongers M, et al (1990) Long-term changes of salt marsh communities by cattle grazing. Vegetatio 89:137-148.

Augustine D, McNaughton S (1998) Ungulate effects on the functional species composition of plant communities: herbivore selectivity and plant tolerance. J Wildl Manage 62:1165-1183.

Bakker JP, Bos D, de Vries Y (2003) To graze or not to graze : that is the question. In: Wolff WJ, Essink $\mathrm{K}$, Kellermann A, van Leeuwe MA (eds) Challenges to the Wadden Sea - Proceedings of the 10th international scientific Wadden Sea Symposium. pp 67-87

Bakker JP, Leeuw J, Dijkema KS, et al (1993) Salt marshes along the coast of The Netherlands. Hydrobiologia 265:73-95. doi: 10.1007/BF00007263

Bates D, Maechler M, Bolker BM, Walker S (2014) Ime4: Linear mixed-effects models using Eigen and S4. J. Stat. Softw. $x x: x x$.

Berg G, Esselink P, Groeneweg M, Kiehl K (1997) Micropatterns in Festuca rubra-dominated saltmarsh vegetation induced by sheep grazing. Plant Ecol 132:1-14.

Boyd LE, Carbonaro DA, Houpt KA (1988) The 24-Hour Time Budget of Przewalski Horses. Appl Anim Behav Sci 21:5-17. doi: 10.1016/0168-1591(88)90098-6

Burnham KP, Anderson DR (2002) Model Selection and Multimodel Inference: a Practical Information-theoretic Approach, 2nd edn. Springer-Verlag, New York.

Cornelissen P, Vulink JT (2015) Density-dependent diet selection and body condition of cattle and horses in heterogeneous landscapes. Appl Anim Behav Sci 163:28-38. doi: 10.1016/j.applanim.2014.12.008

Crawley MJ (1983) Herbivory - The Dynamics of Animal-Plant Interactions (Studies in Ecology 10). Blackwell Scientific, Oxford

Dale AJ, Mayne CS, Laidlaw AS, Ferris CP (2008) Effect of altering the grazing interval on growth and utilization of grass herbage and performance of dairy cows under rotational grazing. Grass Forage Sci 63:257-269.

Dixon PM (2002) Nearest neighbor methods. Encycl. environmetrics 1-26.

Dumont B, Garel JP, Ginane C, et al (2007a) Effect of cattle grazing a species-rich mountain pasture under different stocking rates on the dynamics of diet selection and sward structure. Animal 1:1042-52. doi: 10.1017/S1751731107000250

Dumont B, Rook AJ, Coran C, Röver KU (2007b) Effects of livestock breed and grazing intensity on biodiversity and production in grazing systems. 2. Diet selection. Grass Forage Sci 62:159-171.

Dumont B, Rossignol N, Loucougaray G, et al (2012) When does grazing generate stable vegetation patterns in temperate pastures? Agric Ecosyst Environ 153:50-56. doi: 10.1016/j.agee.2012.03.003

Duncan P, Foose TJ, Gordon IJ, et al (1990) Comparative nutrient extraction from forages by grazing bovids and equids : a test of the nutritional model of equid / bovid competition and coexistence. Oecologia 84:411-418. 
Elizalde-Arellano C, Lopez-Vidal JC, Hernandez L, et al (2012) Home Range Size and Activity Patterns of Bobcats (Lynx rufus) in the Southern Part of their Range in the Chihuahuan Desert, Mexico. Am Midl Nat 168:247-264.

\section{ESRI (2011) ArcGIS Desktop: Release 10.}

Esselink P, Fresco LFM, Dijkema KS (2002) Vegetation change in a man-made salt marsh affected by a reduction in both grazing and drainage. Appl Veg Sci 5:17-32. doi: 10.1658/14022001(2002)005[0017:VCIAMM]2.0.CO;2

Esselink P, Zijlstra W, Dijkema KS, van Diggelen R (2000) The effects of decreased management on plant-species distribution patterns in a salt marsh nature reserve in the Wadden Sea. Biol Conserv 93:61-76.

Ferreira LMM, Celaya R, Benavides R, et al (2013) Foraging behaviour of domestic herbivore species grazing on heathlands associated with improved pasture areas. Livest Sci 155:373-383. doi: 10.1016/j.livsci.2013.05.007

Gibb MJ, Huckle CA, Nuthall R, Rook AJ (1999) The effect of physiological state (lactating or dry) and sward surface height on grazing behaviour and intake by dairy cows. Appl Anim Behav Sci 63:269-287. doi: 10.1016/S0168-1591(99)00014-3

Gordon IJ (1989) Vegetation Community Selection By Ungulates On The Isle Of Rhum. II . Vegetation Community Selection. J Appl Ecol 26:53-64.

Hampson BA, Morton JM, Mills PC, et al (2010) Monitoring distances travelled by horses using GPS tracking collars. Aust Vet J 88:176-181. doi: 10.1111/j.1751-0813.2010.00564.x

Jensen A (1985) The Effect of Cattle and Sheep Grazing on Salt-Marsh Vegetation at Skallingen, Denmark. Vegetatio 60:37-48. doi: 10.1007/BF00053910

Karmiris I, Platis PPD, Kazantzidis S, Papachristou TG (2011) Diet selection by domestic and wild herbivore species in a coastal Mediterranean wetland. Ann Zool Fennici 48:233-242.

Kiehl K, Eischeid I, Gettner S, Walter J (1996) Impact of different sheep grazing intensities on salt marsh vegetation in northern Germany. J Veg Sci 7:99-106.

Kiehl K, Esselink P, Gettner S, Bakker JP (2001) The impact of sheep grazing on net nitrogen mineralization rate in two temperate salt marshes. Plant Biol 3:553-560.

Kiehl K, Schröder H, Stock M (2007) Long-term vegetation dynamics after land-use change in Wadden Sea salt marshes. Coastline Reports 7:17-24.

Kleyer M, Feddersen H, Bockholt R (2003) Secondary succession on a high salt marsh at different grazing intensities. J Coast Conserv 9:123-134.

KrysI LJ, Hubbert ME, Sowell BF, et al (1984) Horses and Cattle Grazing in the Wyoming Red Desert .1. Food-Habits and Dietary Overlap. J Range Manag 37:72-76.

Lellau TF, Liebezeit G (2001) Alkaloids, saponins and phenolic compounds in salt marsh plants from the Lower Saxonian Wadden Sea. Senckenbergiana maritima 31:1-9. doi: 10.1007/BF03042831

Mandema FS, Tinbergen JM, Ens BJ, Bakker JP (2013) Livestock grazing and trampling of birds' nests: an experiment using artificial nests. J Coast Conserv 17:409-416. doi: 10.1007/s11852-013$0239-2$

Mandema FS, Tinbergen JM, Ens BJ, Bakker JP (2014) Spatial Diversity in Canopy Height at Redshank and Oystercatcher Nest-Sites in Relation to Livestock Grazing. Ardea 101:105-112. doi: 10.5253/078.101.0205 
Menard C, Duncan P, Fleurance G, et al (2002) Comparative foraging and nutrition of horses and cattle in European wetlands. J Appl Ecol 39:120-133.

Metera E, Sakowski T, Sloniewski K, Romanowicz B (2010) Grazing as a tool to maintain biodiversity of grassland - a review. Anim Sci Pap Reports 28:315-334.

Meyer H, Fock H, Haase A, et al (1995) Structure of the Invertebrate Fauna in Salt Marshes of the Wadden Sea Coast of Schleswig-Holstein Influenced by Sheep-Grazing. Helgolander Meeresuntersuchungen 49:563-589. doi: 10.1007/BF02368383

Nolte S, Esselink P, Bakker JP (2013) Flower production of Aster tripolium is affected by behavioral differences in livestock species and stocking densities: the role of activity and selectivity. Ecol Res 28:821-831.

Nolte S, Esselink P, Bakker JP, Smit C (2015) Effects of livestock species and stocking density on accretion rates in grazed salt marshes. Estuar Coast Shelf Sci 152:109-115. doi: 10.1016/j.ecss.2014.11.012

Nolte S, Esselink P, Smit C, Bakker JP (2014) Herbivore species and density affect vegetationstructure patchiness in salt marshes. Agric Ecosyst Environ 185:41-47. doi: 10.1016/j.agee.2013.12.010

Norris K, Cook T, O'Dowd B, Durdin C (1997) The density of redshank Tringa totanus breeding on the salt-marshes of the Wash in relation to habitat and its grazing management. J Appl Ecol 34:999-1013.

Pepin D, Morellet N, Goulard M (2009) Seasonal and daily walking activity patterns of free-ranging adult red deer (Cervus elaphus) at the individual level. Eur J Wildl Res 55:479-486.

Pinheiro J, Bates D, DebRoy S, Sarkar D (2013) nlme: Linear and Nonlinear Mixed Effects Models. R package version 3.1-108.

Provenza FD, Balph DF (1987) Diet learning by domestic ruminants: Theory, evidence and practical implications. Appl Anim Behav Sci 18:211-232.

Putman RJ, Fowler AD, Tout S (1991) Patterns of use of ancient grassland by cattle and horses and effects on vegetational composition and structure. Biol Conserv 56:329-347. doi: 10.1016/0006-3207(91)90065-H

R Development Core Team (2013) R: A language and environment for statistical computing. R Foundation for Statistical Computing, Vienna, Austria

Rickert C (2011) Microlepidoptera in salt marshes - Life history, effects of grazing, and their suitability as ecological indicators. Suppl zu Faun ökologische Mitteilungen 37:5-124.

Rickert C, Fichtner A, van Klink R, Bakker JP (2012) $\alpha$ - and $\beta$-Diversity in Moth Communities in Salt Marshes Is Driven By Grazing Management. Biol Conserv 146:24-31. doi: 10.1016/j.biocon.2011.11.024

Rook AJ, Dumont B, Isselstein J, et al (2004) Matching type of livestock to desired biodiversity outcomes in pastures - a review. Biol Conserv 119:137-150. doi: 10.1016/j.biocon.2003.11.010

Rutter SM, Orr RJ, Yarrow NH, Champion RA (2004) Dietary preference of dairy cows grazing ryegrass and white clover. J Dairy Sci 87:1317-1324. doi: 10.3168/jds.S0022-0302(04)73281-6

Schröder HK, Kiehl K, Stock M (2002) Directional and non-directional vegetation changes in a temperate salt marsh in relation to biotic and abiotic factors. Appl Veg Sci 5:33-44.

Silliman BR, Mozdzer T, Angelini C, et al (2014) Livestock as potential biological control agent for an invasive wetland plant. PeerJ. doi: 10.7717/peerj.567 
Stewart GB, Pullin AS (2008) The relative importance of grazing stock type and grazing intensity for conservation of mesotrophic "old meadow" pasture. J Nat Conserv 16:175-185. doi: 10.1016/j.jnc.2008.09.005

ter Braak CJF, Šmilauer P (2002) CANOCO Reference Manual and CanoDraw for Windows User's Guide: Software for Canonical Community Ordination (Version 4.5). Sect Permut Methods Microcomput Power, Ithaca, New York 10. doi: citeulike-article-id:7231853

van Klink R, Nolte S, Mandema FS, et al (2016) Effects of grazing management on biodiversity across trophic levels-The importance of livestock species and stocking density in salt marshes. Agric Ecosyst Environ 235:329-339. doi: 10.1016/j.agee.2016.11.001

Van Soest PJ, Robertson JB, Lewis BA (1991) Methods for Dietary Fiber, Neutral Detergent Fiber, and Nonstarch Polysaccharides in Relation to Animal Nutrition. J Dairy Sci 74:3583-3597.

Veeneklaas RM, Dijkema KS, Hecker N, Bakker JP (2013) Spatio-temporal dynamics of the invasive plant species Elytrigia atherica on natural salt marshes. Appl Veg Sci 16:205-216.

Vulink JT, Drost HJ (1991) A causal analysis of diet composition in free ranging cattle in reeddominated vegetation. Oecologia 88:167-172.

Westhoff V, Hobohm C, Schaminée JHJ (1993) Rote Liste der Pflanzengesellschaften des Naturraumes Wattenmeer unter Berücksichtigung der ungefährdeten Vegetationseinheiten. Tuexenia 13:109-140.

Zuur AF, leno EN, Walker NJ, et al (2009) Mixed effects models and extensions in Ecology with R. Springer Science+Business Media 
Table 1: Model results for the generalized least squares models and generalized linear models investigating the effect of livestock species, stocking density and Block on the average NDF in the animal diet and the average time spent grazing and distance travelled per day. Bold letters indicate the best model.

\section{Model}

Livestock * Density + Block Livestock * Density

Livestock + Density + Block

Density + Block

Livestock + Block

Livestock + Density

Livestock

Density

Block

\begin{tabular}{|ccc} 
& & \\
& & \\
& & \\
df & AIC & $\Delta$ AIC \\
10 & 2148.74 & 0.95 \\
9 & 2147.79 & 0.00 \\
9 & 2149.43 & 1.64 \\
8 & 2157.44 & 9.65 \\
8 & 2157.58 & 9.79 \\
8 & 2148.35 & 0.57 \\
7 & 2156.15 & 8.36 \\
7 & 2156.28 & 8.50 \\
7 & 2166.03 & 18.25
\end{tabular}

\begin{tabular}{l|cccc|}
\multicolumn{5}{c}{ Activity } \\
\multicolumn{5}{c}{$\mid \begin{array}{c} \\
\text { Akaike }\end{array}$} \\
weight & df & AIC & DAIC & $\begin{array}{c}\text { Akaike } \\
\text { weight }\end{array}$ \\
0.05 & 6 & 247.69 & 3.11 & 0.10 \\
0.05 & 5 & 250.11 & 5.53 & 0.03 \\
0.12 & 5 & 246.50 & 1.92 & 0.18 \\
0.02 & 4 & 290.76 & 46.17 & 0.00 \\
0.28 & 4 & 244.58 & 0.00 & 0.48 \\
0.13 & 4 & 248.80 & 4.22 & 0.06 \\
0.30 & 3 & 246.87 & 2.28 & 0.15 \\
0.02 & 3 & 289.61 & 45.03 & 0.00 \\
0.04 & 3 & 288.77 & 44.18 & 0.00
\end{tabular}

